\title{
Capstone Projects With Limited Budget as an Effective METHOD FOR EXPERIENTIAL LEARNING
}

\author{
L. Balan*, T. Yuen, D. Centea, and Ishwar Singh \\ School of Engineering Technology, McMaster University, Hamilton, Ontario, Canada \\ *Corresponding author: balanl@mcmaster.ca
}

\begin{abstract}
This paper describes a method that is used in School of Engineering Technology Department at McMaster University to promote experiential learning at undergraduate level through capstone projects.

The goal of this paper is to demonstrate that capstone projects with limited budget can be effectively used to implement experiential learning methodology to engineering students.

According to this methodology, students work in groups of three over two academic terms, to complete capstone projects that require designing, building, testing, and prototyping a final product. The methodology is addressed from the perspective of experiential learning theory, and several project cost-reducing strategies are presented.

Selected results from student capstone projects at McMaster University are presented and discussed. Results indicate that capstone projects can be successfully implemented into experiential learning methodology when adequate strategies for reducing the project costs are considered.
\end{abstract}

Keywords: Experiential Learning, Capstone Projects, Project Based Learning.

\section{INTRODUCTION}

Finding different pedagogical methods that trigger students' passion for learning and increase the learning outcomes effectively is one of the main goals of many people in teaching community.

Experiential learning is a teaching methodology based on learning from direct experience through reflection, observation, and practice, as opposed to the traditional academic learning that generally relies on acquiring information through study.

At the core of experiential learning is Kolb's theory composed of the four-stage learning cycle: concrete experience, reflective observation, abstract conceptualization, and active experimentation [1].
Two well-known implementations of experiential learning are Problem-based learning (PBL) and Projectbased learning (PjBL).

The PBL pedagogical method actively engages students in constructing knowledge by working in groups to solve given problems. Unlike traditional lecturecentered learning methods, the PBL method is studentcentered.

Blumenfeld [2] defines PjBL pedagogical method as "a comprehensive perspective focused on teaching by engaging students in investigation. Within this framework, students pursue solutions to non-trivial problems by asking and refining questions, debating ideas, making predictions, designing plans and/or experiments, collecting and analyzing data, drawing conclusions, communicating their ideas and findings to others, asking new questions and creating artifacts".

Thomas [4] explains that project-based learning requires "complex tasks, based on challenging questions or problems, that involve students in design, problemsolving, decision making, or investigative activities; give students the opportunity to work relatively autonomously over extended periods of time; and culminate in realistic products or presentations".

By definition, a capstone project is a comprehensive assignment that serves as a culminating academic experience for students, typically during their final year of their program of study. "Capstone projects are generally designed to encourage students to think critically, solve challenging problems, and develop skills such as oral communication, public speaking, and research skills" [5].

The benefits of using experiential learning in teaching undergraduate students are demonstrated by many scholars and published in various journals and papers. The PBL and PjBL methods produce better learning outcomes, increase student satisfaction, and develop team collaboration among group members.

One of the major benefits of capstone-projects resides is their interdisciplinary characteristic. In most cases, students are asked to apply different skills or investigate 
issues across several subject areas or few domains of knowledge.

Nevertheless, experiential learning through capstone projects method has its own disadvantages, too. Some studies suggest that although $\mathrm{PjBL}$ seems to be a beneficial engaging instructional approach, it can also put a lot of stress on the instructors due to the complexity of student guidance required and the challenge encountered in assessing student work.

Other authors suggest that capstone projects can be expensive and often they need industrial sponsorship, or significant financial support either from the university or from the students themselves [3].

This paper outlines few methods that can be used to reduce the cost of capstone projects, while still preserving the experiential learning objectives. Results of the implementation of these methods at School of Engineering Technology at McMaster University are presented as well.

Through capstone project experimentation, students have the opportunity to build and test their design. By adding the budget constraint into the account, students often learn that their design has to be refined. This observation leads to new concrete experiences for the students, and so, the Kolb's learning cycle is repeated several times.

\section{EXPERIENTIAL LEARNING THROUGH LOW-COST CAPSTONE PROJECTS}

\subsection{Methodology}

The method described in this paper has been applied to a 4-th year course offered in the Faculty of Engineering at McMaster University. The course spans over two consecutive academic terms.

In this course, students working in groups of three are asked to select a topic of their choice for a capstone project. One of the initial constraints requires this project to be completed under a limited budget (typically $\$ 250$ CAD per team).

The complexity of the proposed project topic is then verified and approved by the course instructor. If necessary, the instructor makes recommendations to modify the initial proposal, to meet specific needs.

As a general rule, the project topic must be complex enough to require students to apply skills or investigate issues across several subject areas learned during their academic program of study. Additional project requirements may be derived from the strategies that will be presented in this paper: project scalability, rapid prototyping, integration of electronic components, modular design, and reusability.
Preferably, the selected capstone projects would include: designing, building, testing, and prototyping. Moreover, students would be asked to perform analysis and engineering calculations to defend their engineering solutions.

The engineering design and simulation analyses are expected to be carried out using various software (CAD modeling, FEA etc.) available at the university. A functional prototype would be built using either traditional manufacturing equipment or rapid prototyping.

In the end, students write a comprehensive report for their project and they give an oral presentation of their achievements to a panel committee.

\subsection{Discussions}

The idea of using a low-budget constraint in conjunction with capstone projects has a dual benefit.

First, the project is affordable without putting a big burn on university's budget. Secondly, a limited budget encourages student to think critically. Under a given budget constraint, students must constantly identify ways to keep project cost low while still meeting project deliverables.

A limited budget will also enforce students to cycle repeatedly through different stages of the experiential learning cycle described in Kolb's theory in order to achieve their goals, as part of their experiential learning process.

\section{STRATEGIES FOR COST REDUCTION OF CAPSTONE PROJECTS}

This section outlines several methods to reduce the cost associated with capstone projects. The strategies to be discussed are: project scalability, rapid-prototyping, electronic component integration, and modular design with re-usability.

\subsection{Project Scalability}

It is quite obvious that physical dimensions of the project have an impact on the manufacturing cost of a prototype. Generally speaking, a bigger product will cost more to produce because it requires more material, more machining time, and perhaps more expensive manufacturing equipment with more operating power and a larger workspace.

It is worth mentioning that one should distinguish between a scalable project and a project with small physical dimensions. A down-scalable project would allow for a reduced prototyping cost, while still 
preserving the original complexity and functionality of the original project.

In our course, we advise students during project selection stage to choose a project topic that can be scaled to a size that can be manufactured with the available resources. To accomplish this, technical specifications of the available manufacturing equipment are communicated to students at the time of topic selection.

For example, we let the students know that the 3D printer available at our facility can print objects up to $8 \mathrm{x}$ $6 \times 6$ inch, with a resolution limited to 0.01 inch along the vertical axis, and with an approximate cost of printing of $\$ 8$ CAD per cubic inch. Similar information is provided for all equipment available in our manufacturing laboratory.

\subsection{Rapid Prototyping}

One of the requirements of the capstone projects is to create a functional prototype of the scaled model. This phase generally takes place during the second term of the course.

We have found that by substituting traditional manufacturing ( $\mathrm{CNC}$, milling, turning, etc.) with 3D printing, the fabrication cost of the prototype can be reduced significantly. As a side note, traditional machining is also called "subtractive manufacturing" because it removes material to create a final product. 3D printing is also referred as "additive manufacturing" in the specialized literature, because it creates parts by adding material through a cycling process.

It is worth emphasizing that the priority of our capstone projects is to make a working prototype, and we are not aiming to optimize an engineering design for manufacturing, or large batch production.

Most 3D printers work using additive layer manufacturing technology, and they use a plastic filament for building a part from a digital model, usually a CAD file. While these machines were quite expensive in the past, they are more affordable nowadays.

The major benefit of using 3D printers for (scaled) capstone projects lays in its easiness of use. Although most 3D printers are relatively slow in producing parts (in the range of $\sim 1$ cubic inch / hour), their setup time is minimal. This is because $3 \mathrm{D}$ printers allow for direct input of CAD model file of the part to be fabricated. On the other side, subtractive machining is faster, but it generally needs significant additional time for fixture setup and pre-processing to generate the tool path needed for machining.

Limitations of current 3D printers include: restricted material selection, strength, and accuracy (resolution) of fabricated part. The most common material available for 3D printing is ABS plastic. Metal printers do exist, but at this moment they are more expensive.
The resolution limitation can be addressed by purchasing of-the-shelf components where more accuracy or strength is needed. For example, fasteners, or moving parts like shafts, bushings, and bearings, can be purchased and accommodated into the design instead of being $3 \mathrm{D}$ printed.

\subsection{Electronic Component Integration}

Capstone projects need to have a certain degree of complexity in order to encourage students to think critically, solve challenging problems, and to develop engineering skills based on their knowledge.

We have determined that by adding electronic components to capstone project, the complexity of the project can be increased with a relatively low cost. Electronic components such as micro-controllers, sensors, LCDs, wireless modules, they all can increase the versatility of a project with a minimal investment.

Mechatronics-type projects are a great choice for capstone projects because they require integration of mechanical components with electronics through programming.

A secondary advantage of using electronic components is their re-usability. Often these components are re-programmable and they can be easily shared among different projects. As more projects are completed a large stock of electronic parts becomes available for further projects.

Typical sensors recommended for capstone projects include reed-switches, optical detectors, proximity sensors, motion detection sensors, force sensors, flex sensors, IR sensors, buzzers, 3-axis accelerometers, tilting sensors, ultrasonic sensors, vibration and linear displacement sensors, 5-position control joystick.

There are many sensor kits available on the market that can be purchased for as little as $\$ 50 \mathrm{CAD}$ for a package of 20 sensors.

These sensors can be further combined with push buttons, LEDs, 7-segment displays, LCDs displays, and micro-controllers to obtain desired functionality. For actuators we recommend DC servo motors, encoders, tachometers, and motor drive chip for controlling and reversing the direction of rotation.

Advanced applications of capstone project may consider blue-tooth modules that allow for input/output communications of different electronic components.

\subsection{Modular Design with Reusability}

Modularity is another smart way to reduce the cost of capstone projects. We recommend students to follow a modular design approach, and to develop sub-components for their projects that can be further interchanged with other potential projects. Alternatively, such sub- 
components can be purchased and used as starting point for several related capstone projects.

The reusability approach works quite well with electronic components which can be easily interchanged among different applications. Off-the-shelf components like electrical motors, drive gears, fasteners, couplers, etc. speed up the design process and they can be reused.

We have found that mechanical sub-assemblies can also be successfully reused in many applications. While the initial cost of a sub-system may be larger than the allocated budget, the investment may pay back if the component is shared among several projects.

A good example would be the purchase of a chassis for a remote controlled (RC) toy car. As it will be shown, the chassis can be utilized as a common starting platform for several related capstone projects like building a selfparking car, autonomous navigation, or forward collision warning system.

\section{EXAMPLES OF LOW-COST CAPSTONE PROJECTS}

In this section of the paper results from student capstone projects are presented from the perspective of cost-reducing strategies discussed.

\subsection{Example 1: Self-Parking Car System}

The goal of this capstone project is to build a nonexpensive, fully-automated, side-parking system for a car. The project was built on a RC chassis platform with built in suspension. The steering mechanism was modified, as part of the design task.

The car uses side mounted sensors to dynamically scan for a proper parking spot. If enough space is detected, the side-parking maneuver is executed. If the scanned space is too small, the side parking procedure is aborted.

The project was built within the allocated amount of $\$ 250$ CAD (chassis included). A picture with completed prototype is shown in Figure 1.

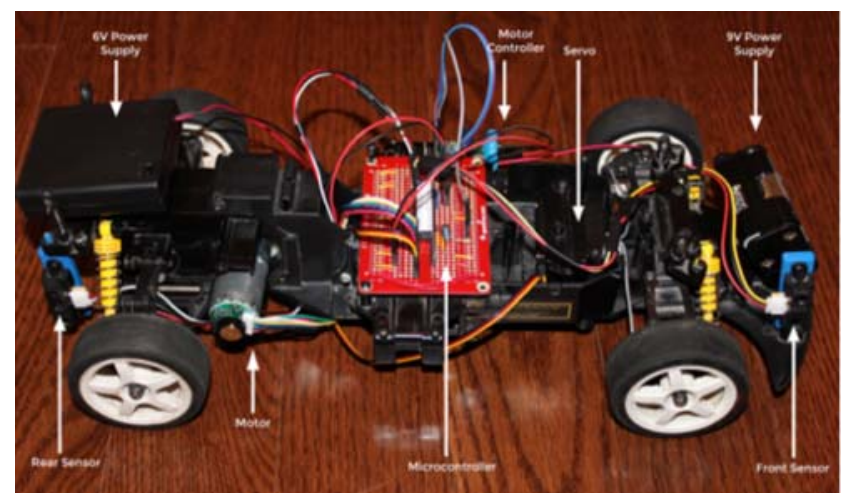

Figure 1: Automated side-parking system built on an RC chassis
Major components include two servo motors (one for left/right steering, and one for forward/reverse motion), one microcontroller, two proximity sensors, two battery packs, and one blue-tooth wireless communication module. The redesigned steering mechanism and the two motor mounting adaptors were 3D printed.

A wireless communication module was added to quickly upload the program onto microcontroller, and to easily change some input parameters. The built system is fully automated, and it does not require user intervention during parking procedure. Figure 2 shows the interface of the computer program, created by the students.

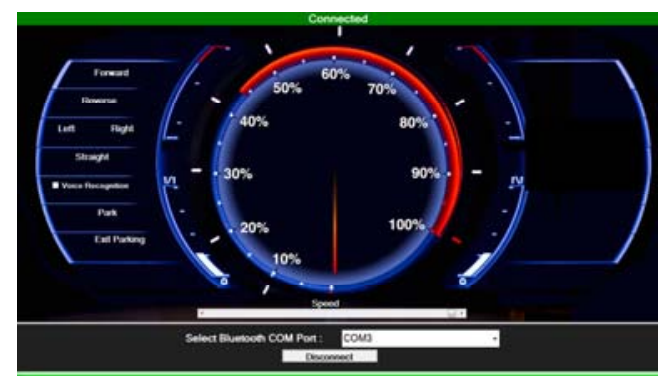

Figure 2: Computer interface for self-parking system

The RC chassis platform along with other components such as servo motors, proximity sensors, microcontroller, and wireless module, can be re-used for other car related capstone projects. Alternatively, with a minimal investment, this project can be further extended to incorporate other types of parking methods.

\subsection{Example 2: User Controlled Spider Robot}

In this capstone project, students designed and built two conceptual versions of an 8-leg robot. The cost for building each robot was within $\$ 140$ to $\$ 160$ CAD. The robot is capable of moving in straight line and to rotate on the spot, based on user command.

Students' work consists of complete engineering design, testing, fabrication, and programming of each unit.

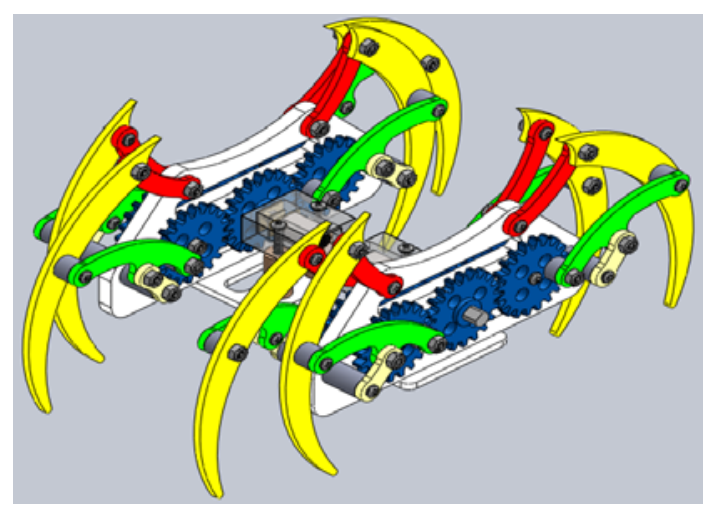

Figure 3: CAD model of spider robot (concept 1) 


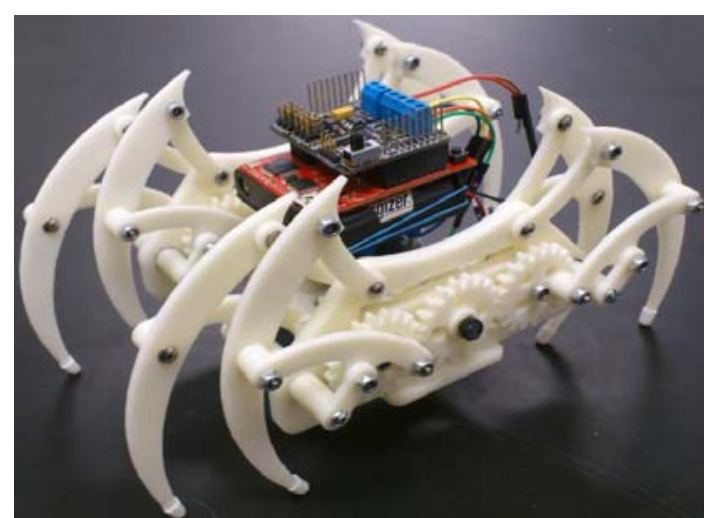

Figure 4: Built prototype of spider robot (concept 1)

The CAD models of the two robots are shown in Figure 3 and Figure 5 and the fabricated prototypes are presented in Figure 4 and Figure 6.

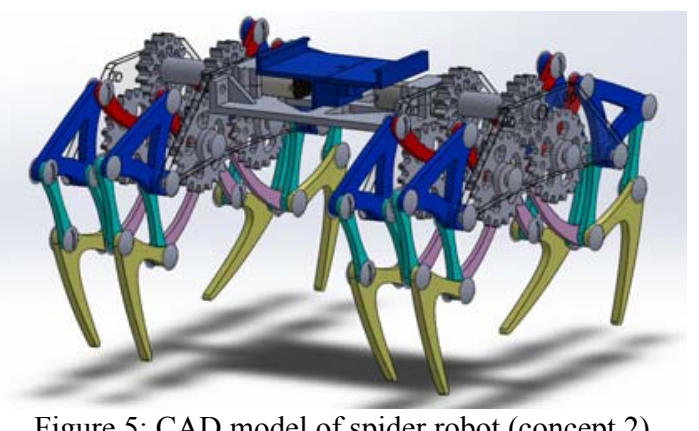

Figure 5: CAD model of spider robot (concept 2)

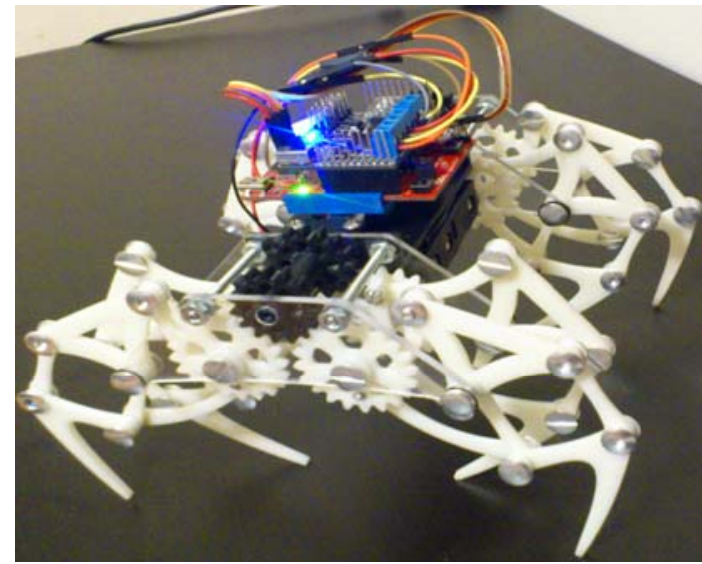

Figure 6: Built prototype for spider robot (concept 2)

Major components for each robot include two servo motors, one microcontroller, one dual motor drive chip, battery pack, fasteners, and electrical connectors.

Robot linkages were all designed from scratch and optimized and 3D printed, whereas fasteners and pins for the joints were purchased. Other purchased subcomponents were the servo motors equipped with gear reductions for increased torque.
For robot control, students presented two solutions: one robot is controlled by a hard wired thumb joystick, while the other one is controlled wirelessly by a cell phone application through a wireless blue tooth module (see Figure 7).

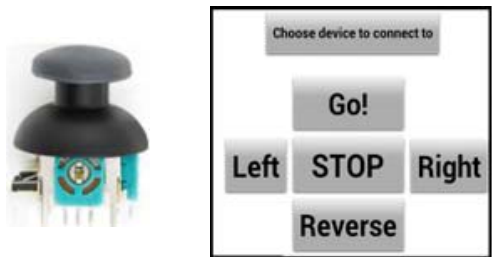

Figure 7: User input devices used: thumb joystick (left), cell phone app (right)

The approximate overall size of each robot is $15 \mathrm{x} 20 \mathrm{x}$ $15 \mathrm{~cm}$, the weight including the battery pack is $600-700$ grams, and the operating (walking) speed $2.5-3.5 \mathrm{~cm} / \mathrm{sec}$.

Completing this project required six cycles through the four-phases of Kolb's theory.

\subsection{Example 3: Robotic Hand}

The goal of this project is to build a robotic hand remotely operated by hardwired push buttons. Each finger uses one actuator (servo motor) to provide opening and closing the hand when a corresponding push button is activated by the user. The designed model and the built prototype are shown in Figure $\mathbf{8}$ and Figure 9, respectively.

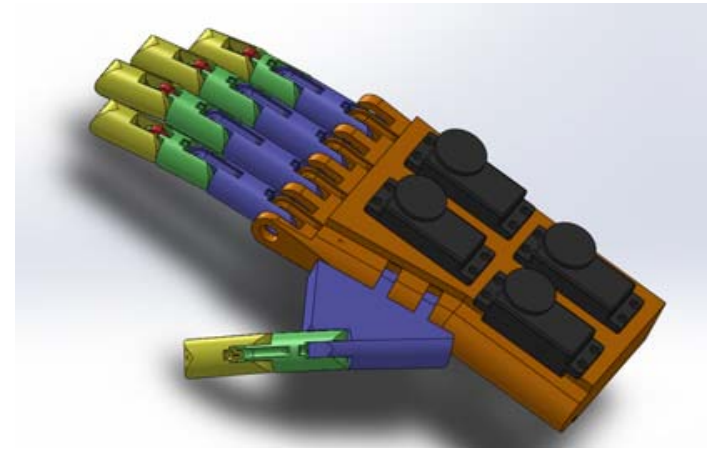

Figure 8: CAD model of robotic hand

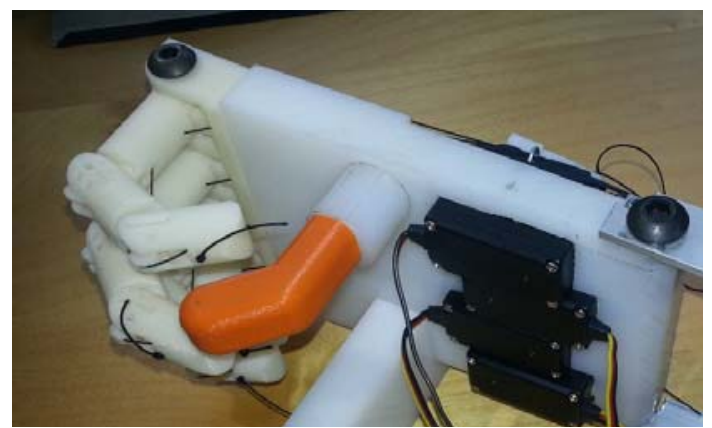

Figure 9: Built prototype of robotic hand 
The project work includes complete engineering design, testing, and prototyping of the hand. Most of the hand parts were 3D printed. The built prototype has only four functional fingers, and a fixed thumb. The project will be carried on by another group of students, for further development.

The controller of the low-cost prosthetic hand operated by hardwired push buttons is shown in Figure 10.

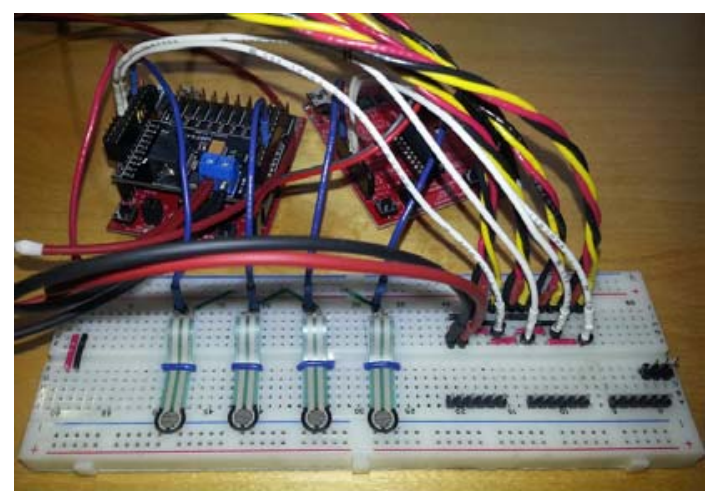

Figure 10: Hardwired controller for robotic hand

The technical solution for hand actuating system chosen by the students is based on strings and position controlled DC servo motors. Other components used in this project are: one microcontroller, four pressure sensors, motor control drive chip, and electrical wire connectors.

This project was built within the allocated project budget of $\$ 250 \mathrm{CAD}$, and it can be further extended. For example, wireless communication can be added for hand control, or feedback sensors can be added to the hand for a controlled gripping force.

\section{CONCLUSSIONS}

In conclusion, experiential learning, as outlined in Kolb's theory, can be effectively implemented through $\mathrm{PjBL}$ method into engineering curriculum without the high-cost that is normally associated to the capstone projects.

Capstone projects are known as a valuable resource for experiential learning methodology because they require an interdisciplinary approach through designing, building, testing, and prototyping a final product, but they often require significant financial support or sponsorship.

In this paper, several strategies for keeping the cost of the capstone projects under control were discussed and analyzed from the perspective of experiential learning theory. The methods discussed in the paper are: project scalability, rapid-prototyping, electronic component integration, and modular design with component reusability.

It has been shown that by adding a low-budget constraint to the project requirements, and by combining it with cost-reducing strategies, a dual benefit can be achieved: the capstone projects become affordable, and the experiential learning of the students can be enhanced.

Results from implementing these methods into a 4-th year course at School of Engineering Technology at McMaster University have been presented and briefly discussed.

Our results conclude that limited-budget capstone projects can be effectively implemented into experiential learning methodology when adequate strategies are considered to minimize the prototyping cost.

\section{References}

[1] Kolb, D, Experiential Learning as the Science of Learning and Development. Englewood Cliffs, NJ: Prentice Hall, 1984

[2] Phyllis C. Blumenfeld, Elliot Soloway, Ronald W. Marx, Joseph S. Krajcik, Mark Guzdial, and Annemarie Palincsar, "Motivating Project-Based Learning: Sustaining the Doing, Supporting the Learning," Educational Psychologist, 26(3\&4), pp. 369-398, 1991.

[3] Emad W. Jassim, "Formulation of Capstone Design Projects for Experiential Learning," Capstone Design Conference June 2-4, Columbus Ohio, 2014

[4] Thomas, J. "A Review of the Research on Project-Based Learning”. The Autodesk Foundation. 2000.

[5] Hidden curriculum (2014, August 26). In S. Abbott (Ed.), The glossary of education reform. Retrieved from http://edglossary.org/hidden-curriculum 